\title{
Quantifying the Carbon Footprint of Lean Waste
}

\author{
Kristen D. Balinski, Katie Grantham \\ Department of Engineering Management and Systems Engineering, \\ Missouri University of Science and Technology, Rolla, USA \\ Email:kadthf@mst.edu,kag@mst.edu
}

Received October 24, 2012; revised November 26, 2012; accepted December 10, 2012

\begin{abstract}
The objective of this paper is to provide a method of quantifying lean wastes in terms of carbon dioxide emissions by using value stream mapping. Lean manufacturing, based on waste identification and reduction, is a growing trend in industry and a proven method of lowering costs. The environmental impact of these wastes can be quantified in a new way by treating green waste as an outcome of lean wastes. Growing environmental concerns are prompting federal government regulation of greenhouse gas or carbon dioxide emissions, as introduced in the American Clean Energy and Security Act of 2009. This bill would have a significant economic impact on manufacturing businesses. And while many carbon footprint calculators are available for citizens to quantify their own emissions, there are currently none available for manufacturing companies to use in order to accurately quantify their carbon dioxide emissions to meet impending governmental regulations.
\end{abstract}

Keywords: Lean Manufacturing; Green Manufacturing

\section{Introduction \& Motivation}

The objective of this paper is to provide a method of quantifying lean wastes in terms of carbon dioxide emissions through the use of value stream mapping. At the urging of concerned environmental scientists, citizens, and consumers, governments are beginning to impose restrictions designed to limit the amount of greenhouse gas emissions in the coming years. A version of the American Clean Energy and Security Act, passed by the House of Representatives in June 2009, mandates a 17\% cut in emissions by 2020 and upwards of an $80 \%$ cut by 2050, based on emissions from 2005 [1].

Since lean manufacturing has long been praised for its waste reduction, it is poised to capitalize on the related "green waste" reduction as has been highlighted by the United States Environmental Protection Agency and authors such as Brett Wills [2-4]. This paper will show connections between wastes of the lean and green worlds and demonstrate how to identify and quantify the green waste inherent in the process in the style of carbon footprint calculators while still adding value to the process. The companies who embrace lean manufacturing will be able to simultaneously embark on lean initiatives that increase their value while measuring and reducing their carbon footprint. This provides an objective green quantification for the company, environmentally conscious consumers, and forms a basis for future government regulations.
In this paper, carbon emissions calculations have been provided in a table of unit conversions for a variety of measurable outcomes of lean wastes. These outcomes were identified by analyzing each lean waste in terms of its outcomes and their connections to green wastes. By incorporating select green measurements into the common lean practice of value stream mapping, companies can easily record their data, combine it with unit conversions, and monitor their $\mathrm{CO}_{2}$ emissions.

\section{Literature Review}

\subsection{Emissions Regulations}

As awareness and acceptance of climate change predictions grows, many consumers, citizens, and governments are becoming increasingly concerned with environmental sustainability. The Intergovernmental Panel on Climate Change (IPCC), a scientific body established by the United Nations Environmental Programme and the World Meteorological Organization, "reviews and assesses the most recent scientific, technical and socio-economic information produced worldwide relevant to the understanding of climate change [5].” Their 2007 report states:

Global atmospheric concentrations of carbon dioxide, methane and nitrous oxide have increased markedly as a result of human activities since 1750 and now far exceed pre-industrial values determined from ice cores spanning many thousands of years [...] The global increases in carbon dioxide concentration are due primarily to fossil 
fuel use and land use change, while those of methane and nitrous oxide are primarily due to agriculture. [...]

Continued greenhouse gas emissions at or above current rates would cause further warming and induce many changes in the global climate system during the 21 st century that would very likely be larger than those observed during the 20th century [6].

In an effort to encourage emission reduction by increasing energy efficiency in the United States, Congress is attempting to pass new laws that limit the amount of emissions companies can release through policies including a "cap and trade" system. In this system, each company will be allowed a set amount of "carbon credits," which measure their allotted emissions. Companies who do not use all of these credits can sell them, thus providing financial incentive to reduce emissions [1]. In addition to US Congressional action, United Nations climate change talks continue their aim to combat global warming on an international level through emissions caps. Such regulation is certain to have an economic impact on manufacturing companies. Part of the solution involves accurate calculations of current emissions, along with understanding how a basis in lean thinking can bring greener results.

\subsection{Lean and Green}

Since its development, lean manufacturing has focused on categorizing and eliminating non-value adding steps, or wastes [7]. This structure lends itself directly to classifying and measuring a product of green waste: carbon dioxide emissions. The link between lean manufacturing and green manufacturing has been explored and found to be a significant effect on the manufacturing process becoming green $[8,9]$.

According to the US Environmental Protection Agency (EPA), "Lean is a business model and collection of methods that help eliminate waste while delivering quality products on time and at least cost [8]." The development of Lean thinking and its roots in the automotive industry has been studied and documented by James P. Womack, Daniel Roos, and Daniel P. Jones in The Machine that Changed the World, and later refined by Womack and Jones in Lean Thinking [10,11]. They have distilled lean thinking into five principles [7].

Many industrial experts point to the prevalence of lean thinking and its ties to green thinking as a method of becoming more green $[2,7,12]$. An Industry Week article states that the 2007 Industry Week/MPI Census of Manufactures found that $70 \%$ of companies are implementing some form of lean, and goes on to outline how companies such as General Electric and Canyon Creek Cabinet Company have found success combining lean and green initiatives, simultaneously demonstrating the popularity of lean and its potential for producing green benefits [9].

In an Industrial Engineer article, Franchetti et al. define six goals of green engineering:

- Select low environmental impact materials;

- Avoid toxic or hazardous materials;

- Choose cleaner production processes;

- Maximize energy and water efficiencies;

- Design for waste minimization;

- Design for recyclability and reuse of materials.

The authors assert that these concepts can be implemented through lean manufacturing and go on to address the related aspects of lean based industrial engineering that can accomplish them [12]. Among them are inventory control, which reduces space needed in a facility, thereby reducing heating, cooling, and energy costs; statistical analysis, including the lean tool of value stream maps; and logistics, an area in which waste can be cut through leaner transport and packaging of goods. Through this analysis, it is apparent that many lean tools exist that can contribute to achieving green engineering goals. What is needed is a framework that can tie lean thinking to quantifiable green outcomes.

\subsection{Lean Value Stream Mapping}

The practice of value stream mapping is an important component of lean manufacturing that allows companies to map material and information flows of an entire process in order to identify wastes [13]. Value stream maps (VSMs) represent either the current state (the present process) or the future state (the process goal). In both states the VSM diagrams the suppliers, consumers, production control, and the inventory and information flows between them. Each value stream activity has a process box in which metrics such as changeover times are written. In Learning to See, Rother and Shook emphasize the importance of physically walking through the process to measure and record data of the current state [13].

When all relevant details are collected, the current state value stream map can be analyzed for lean waste. Improvements to the process are found and documented in a future state map, which represents the process goal. Modifications are made to meet this goal, and the value stream mapping method is periodically repeated to further decrease waste.

As an existing and well-established recording tool, value stream mapping is in a prime position to aid in tracking green wastes. By incorporating select additional data, this traditional lean tool can be utilized in new ways. The EPA has addressed this in some of their lean publiccations [3,4]. The Lean and Environment Toolkit suggests weighing the amount of scrap generated in each step of a process. 


\subsection{Green Wastes and Green Stream Mapping}

In addition to lean wastes, some have taken to calling out specific green wastes, which in similar fashion can be measured and systematically reduced. According to author Brett Wills, green waste categories are: energy, water, materials, garbage, transportation, emissions, and biodiversity [2]. Metrics are specific to each waste; water is measured in gallons used, energy in kilowatt-hours, etc. In his approach, the traditional lean tool Value Stream Map is reinvented as a Green Stream Map. Wills argues that mapping the process and measuring green wastes through each step can allow reduction in the same way that lean wastes are decreased [2].

\subsubsection{Wills' Green Wastes}

Wills thoroughly explains each of his green wastes, highlighting both monetary and environmental effects. Energy "specifically refers to energy and fuels (such as natural gas) used to power electrical and mechanical devices." It is considered to be waste when overused, if it comes from a "dirty" source, or when bought from an outside source [2]. Water is a green concern because of the finite supply of fresh water. The overuse of water is a waste, in financial terms for the expense of consuming fresh and disposing of contaminated water, and in depletion of it as a resource [2]. "Material waste comes from a global design flaw-designing virgin raw materials into products that are designed to end up in a landfill [2]." Wills argues that companies should design for reuse, using a "cradle to cradle" concept. Garbage is an obvious green waste, and includes anything that is thrown away. Landfill, recycling, and incineration all produce greenhouse gas emissions. Transportation includes transport of people, materials, supplies, and finished products. Emissions captures those directly "created at your location, such as inside that oven by baking or cooking items containing volatile organic compounds (VOCs) or other toxins that are then exhausted into the atmosphere." Biodiversity waste is created when a disruption is caused in the environment - such as removing trees when building a new factory or through a continuous activity like storing garbage or overharvesting.

This comprehensive list of green wastes address environmental concerns including climate change, natural resource sustainability, and wildlife preservation. Unfortunately, such a broad focus could prove costly for many companies.

\subsubsection{Green Stream Mapping}

The procedure for creating a Green Stream Map closely resembles that for a Value Stream Map; the initial structure of diagramming suppliers, customers, value stream activities and information flow is identical. However, it focuses solely on green waste in each step and is not in- tended as a tool to make the process more lean. For example, process boxes contain only green waste data and inventory flow is not modeled. Also, the production control diagram is reinterpreted as "Admin \& Support," often referred to as the "overall building," and encompasses building activities external to the manufacturing process. If a green waste is identified in a value stream activity, or in the overall building section, its symbol is recorded in the process box.

The true waste measurement and elimination phase then begins through completion of waste-specific worksheets provided by Wills. A series of steps for each waste outline the systematic identification, measurement, and elimination of each through the value stream and throughout the entire building. For example, the steps for eliminating material waste are shown in Table 1. These steps are recorded in the worksheets provided, including the current state worksheet as seen in Table 2. Steps 1-4 refer to the current state Green Stream Map, while Step 5 is part of the future state.

The method of identifying and measuring material waste is highly detailed, requiring information on material makeup (ideally to the level of $100 \mathrm{ppm}$ ) and classification as technical or biological nutrients. Step 4 calls for assessment of the environmental and societal impact of materials, which Wills describes as follows:

Finding out what impact the material is having on the environment and human health can be approached in a few different ways. Research the Web by searching for "environmental impact or human health impact of [material $x$ ]" or "effect of [material $x$ ] on fish life." Approach local environmental organizations, nongovernmental organizations (NGOs), and government organizations to ask for help. The information is out there and, with a little effort, you can find it. Once you know the environmental impact a material can have on the environment, you then want to follow the cradle-to-cradle process of rating it using a color code [.]

The color-coded ratings are defined in Table 3 . This means of identifying and measuring material waste is repeated for each value stream activity and for the entire building. Each of the other six wastes has its own steps

Table 1. Wills' material waste elimination steps.

\footnotetext{
Material

Step 1: Identify the input and output of materials in each activity of your value stream as well as in the overall building.

Step 2: Measure the recycled/recyclable and compostable content of each material input and output.

Step 3: Classify each material input and output as a biological nutrient, and technical nutrient, or neither.

Step 4: Assess materials according to their impact on environment and society.

Step 5: Phase out materials with negative environmental impact.
} 
Table 2. Wills' material waste elimination worksheet.

Material waste elimination worksheet

Activity or area: $\quad$ Value stream activity 1: stamping

Current state

\begin{tabular}{|c|c|c|c|c|c|c|c|c|}
\hline \multicolumn{2}{|c|}{ Identify } & \multicolumn{7}{|c|}{ Measure } \\
\hline \multicolumn{2}{|c|}{ Input } & Output & \multicolumn{2}{|c|}{ Material makeup } & \multicolumn{3}{|c|}{ Classify } & \multirow{2}{*}{ Assess } \\
\hline Item \& Qty & Material makeup & Item & Input & Output & Tn & $\mathrm{Bn}$ & LF & \\
\hline Steel coil (2 per day) & $100 \%$ cold rolled & Frame & $25 \%$ recycled & $100 \%$ recyclable & $\mathrm{X}$ & & & Yellow \\
\hline
\end{tabular}

Table 3. Wells' material waste ratings.

\begin{tabular}{cl}
\hline Category & \multicolumn{1}{c}{ Description } \\
\hline Green & $\begin{array}{l}\text { Little or no risk to environment or human health from } \\
\text { using this substance. }\end{array}$ \\
Yellow & $\begin{array}{l}\text { Low to moderate risk associated with using this material. } \\
\text { Unless you can substitute this material with one that is } \\
\text { rated green, it is acceptable for use. }\end{array}$ \\
Red & $\begin{array}{l}\text { High impact and risk to the environment and human health } \\
\text { from using this material. A strategy for phasing out this } \\
\text { material and replacing it with a green or yellow material } \\
\text { needs to be developed. }\end{array}$ \\
Gray & $\begin{array}{l}\text { Risk data is missing or incomplete. Further investigation } \\
\text { and research is needed in order to rate the material. }\end{array}$ \\
\hline
\end{tabular}

and worksheets. Ultimately, data from the worksheets is transferred to the Green Stream Map. Additional worksheets are used to reduce green wastes and achieve the future state (Step 5, in this case).

Although this method is beneficial in understanding where green wastes appear in the process, individualized metrics make it difficult to judge the overall green impact, as well as the relative effects of each green waste. Some of Wills' ratings, such as the color-coded assessment of materials, are also highly subjective. Utilizing carbon dioxide emissions as the standard metric accomplishes the task of clearly and objectively quantifying the "greenness" of each part of the process and doing so while remaining consistent with metrics associated with emissions legislation.

Wills' method also requires major time and personnel commitments from the manufacturing company. In addition to the time consuming research required just to calculate material waste, Wills' suggestions include hiring a professional energy auditor for an energy assessment and consulting environmental firms to determine the amount of trees and wildlife that were affected by the construction of the company's facilities. His commitment to the environment is respectable, and some companies who are equally committed will no doubt find his method to be right for them.

Yet despite his use of lean tools, Wills does not address the reduction of lean waste that has been a verified technique of adding value. For those companies that want —or are required — to reduce their carbon footprint but are concerned by cost, using the proven practice of lean thinking combined with green measurements and conversion factors to calculate emissions can be a low effort alternative.

\subsection{Current Carbon Footprint Calculators}

Carbon footprint calculators have become an important tool in increasing public awareness of how daily choices can effect greenhouse gas emissions. Time magazine lists the carbon footprint as one of The 50 Best Inventions of 2009 [14]. Anyone today can $\log$ onto the Internet and find a calculator that will estimate their individual or household carbon footprint. However, non-residential and accurate calculators are still lacking.

Eight online carbon footprint calculators were analyzed in an effort to benchmark current options. Five of these are intended for residential use while the remaining three are specific to businesses and organizations. Residential applications, such as the EPA Household Emissions Calculator, require user input regarding home energy use, travel information, and waste data [9]. This particular site also suggests and calculates scenarios to lower your emissions. The Global Footprint Network calculator does not allow for numeric input, but prompts users to answer on a scale of options [15]. Similarly, the Nature Conservancy uses only your zip code and type of home to estimate a starting footprint, then bases the remainder on questions that only allow for subjective answers [16]. Carbonify.com does use numeric input, but does not take into account as many categories as others [17]. CarbonFootprint.com, on the other hand, incorporates all necessary categories - heating options, transportation including public transit, and secondary emissions such as from food and waste, among others - and lets the user input figures directly from their utilities bill [18]. Despite some differences in techniques, all residential calculators displayed the final carbon footprint in terms of $\mathrm{CO}_{2}$, either in tons or pounds.

Non-residential calculators are more difficult to come by. The three analyzed all provide results in tons of carbon dioxide yet their level of detail can easily distinguish them from each other. CarbonMe.org focuses almost solely on transportation, specifically employee commutes 
and air travel [19]. Climate Trust included infrastructure, transportation, and shipping in its calculations-more comprehensive but still not sufficient to fully quantify a manufacturing process [20]. The Seattle Climate Partnership incorporates energy, transport, materials, and waste data into its calculator. Exact data is encouraged, but estimates can also be used if necessary. Unfortunately, this calculator is designed specifically for the Seattle area, with energy information especially for that region [21].

From this analysis it is evident that a carbon footprint calculator must be specially designed for a lean manufacturing process. Current methods will be used as reference, but they must be expanded on in order to adequately quantify the many steps of a manufacturing process.

\section{Methodology}

\subsection{Linking Lean Wastes and Green Wastes}

This approach to quantify carbon dioxide emissions of a process begins with lean wastes. The concept of waste is integral to lean thinking - in order to add value, waste must be reduced, with the ultimate goal of being completely eliminated. For the purposes of this paper, lean wastes have been identified as the Toyota Seven Wastes: transport, inventory, over production, motion, over processing, defects, and waiting [22]. Some, including author Brett Wills, propose a combination of "lean and green" that adds "green" as the eighth lean waste category [2]. Alternatively, this approach treats green waste as an outcome of each of the Toyota Wastes. Recognizing green waste as a product of leans wastes, much as overspending is seen as a product of lean wastes, underscores the complex yet overlapping relationships between lean and green.

\subsubsection{Analyzing Lean Wastes}

With the intent of calculating a carbon footprint in mind, early work in this approach began by breaking lean wastes into manageable outcomes that result in greenhouse gas (GHG) emissions. These heat-trapping GHG emissions stem from natural and human created sources such as burning fossil fuels for electricity, transportation, or production of resources. While additional factors influence environmental sustainability in terms of plant and wildlife health, for example, this approach focuses on the quantifiable GHG emissions that governmental regulations address.

Each lean waste was analyzed for green outcomes that ultimately result in GHG emissions. For instance, over production describes the waste resulting from producing too much of a product or producing it too soon; this leads to the cost-inducing lean outcome of selling the product at a reduced price, if at all, and increasing the on site inventory, which adds no value. This also leads to the green outcomes of excess production time, which requires more energy for machine operation; additional storage, and therefore space that needs to be lit, heated, or cooled; and scrap in the form of material waste to be recycled, incinerated, or deposited in a landfill.

Similarly, inventory can be traced to storage and scrap, in this case also including raw materials or chemicals that may have a shelf life and could require more environmentally wasteful forms of disposal. Transport of goods and materials is costly, and the obvious green outcome can be described as "shipping" and accounts for the fuel burned. Also, production of the packaging used in transport produces emissions, and is designated as "packaging scrap." Defects bring about material scrap and cause excess production time to re-work parts. The most significant green outcome of motion, waiting, and over processing is time; in the case of motion and waiting this refers to the time the building is lit, heated, or cooled, and in the case of over processing it also includes machine use.

Through this analysis green outcomes were listed for each waste, as summarized in Table 4 , and then consolidated into the four major categories of time, storage, shipping and scrap, shown and further described in Table 5. Storage is an outcome of excess inventory, which requires additional space with energy-using lighting, heating, and cooling needs. Time refers both to production time, including the energy used in the production process, and to additional time the building must be lit, heated, and cooled. Scrap takes into account the material waste of a process, including emissions from production of that material as well as emissions from its recycling or disposal. Shipping addresses the fuel burned in transportation of goods and products to and from the site.

Table 5 summarizes these results and also specifies measurements associated with each. These metrics refer to units companies can readily use to track these categories and calculate their carbon footprint. These green outcome categories serve as the first step from lean wastes to their associated carbon emissions. They, in turn, are translated into categories of green waste, as seen in the next section.

\subsubsection{Translation to Green Waste}

Green outcome categories are an important first step in describing the connections between lean wastes and the carbon footprint of a process. Their primary purpose is to serve as a link between lean wastes and the green waste inherent in each of those lean wastes. Due to some overlap in their associated metrics and in order to provide more clear categories, it makes sense to translate these green outcomes into a set of defined green wastes. Author 
Table 4. Green outcomes of lean wastes.

\begin{tabular}{lll}
\hline Toyota seven wastes & Lean description & Green outcome \\
\hline Over production & $\begin{array}{l}\text { A product that cannot be sold, or is sold at a reduced price, producing a } \\
\text { product before the customer needs it }\end{array}$ & Storage, excess production time, scrap \\
Inventory & Excess inventory must be stored, ties up cash & Storage, raw material scrap (shelf life) \\
Transport & Unnecessary movement is wasteful, potential damage to product & Travel, packaging scrap \\
Defects & Re-work is costly, as is sorting and inspecting, and recycling & Scrap, excess production time \\
Motion & Excess operator motion can cause injury and incur costs & Time \\
Over processing & Extra processing does not always add value to product & Excess production time \\
Waiting & Operators should not wait on machines & Time \\
\hline
\end{tabular}

Table 5. Green outcome results and measurements.

\begin{tabular}{|c|c|c|c|}
\hline Green outcome & Result & Measurable outcome & Metric \\
\hline Storage & More space needed & Energy used for heating/cooling/lighting space & $\mathrm{kWh}$ \\
\hline Time & More shifts, equipment runs longer & Energy used for heating/cooling/lighting and running equipment & $\mathrm{kWh}$ \\
\hline Travel & Vehicles & Fuel, efficiencies & gallons/mile \\
\hline Scrap & Material production, recycling, disposal & Energy used to recycle or dispose & $\mathrm{lbs}$, cubic $\mathrm{ft}$ \\
\hline
\end{tabular}

Brett Wills' green wastes-energy, water, material, garbage, transportation, emissions, and biodiversity-were found to represent a comprehensive overview of environmental sustainability metrics.

However, not all of these green wastes are relevant in quantifying a carbon footprint based solely on emissions. Green wastes were examined for their relevance to greenhouse gas emissions. Energy use almost always depends on processes, such as burning coal or natural gas, that produce GHG emissions. Likewise, transportation relies primarily on burning fuels, which results in carbon emissions. Material and garbage can be measured in terms of their carbon emissions associated with original material production and their type of disposal or recycling.

On the other hand, water and biodiversity measure factors that affect the environment, but not in terms of carbon emissions. And while the emissions category of green waste would appear to be significant, most emissions produced on-site, such as volatile organic compounds, have negligible global warming implications.

Results from this analysis and links between the Seven Toyota Wastes and Wills' green wastes were analyzed and the relations are found in Tables 6 and 7. Storage and time are traced to energy - the electricity or fuel used in the facility. Shipping is defined by the green waste of transportation, which measures fuel use of methods of transport. Scrap is divided into material and garbage wastes, which are both categories of physical components but are distinguished by where they are disposed. Garbage is disposed of by the company, whereas material is sent off site as part of the product or its packaging.
Table 6. Translating green outcomes to green wastes.

\begin{tabular}{cc}
\hline Green outcome & Green waste \\
\hline Storage & Energy \\
Time & Energy \\
Shipping & Transportation \\
Scrap & Material \\
& Garbage \\
\hline
\end{tabular}

Table 7. Relations of lean and green wastes.

\begin{tabular}{cc}
\hline Lean waste & Green waste \\
\hline Transport & Transportation \\
& Material \\
Defects & Garbage \\
Over production & Energy \\
Inventory & Energy \\
Motion & Energy \\
Over processing & Garbage \\
Waiting & Energy \\
\hline
\end{tabular}

Translating lean wastes to green wastes shows how these environmental factors are in fact part of the original lean wastes and not an unrelated outcome. In addition to showing this relevance, defined green wastes are helpful in practice to identify what to look for and which measurements to record during the data collection stage of value stream mapping. While green wastes are allocated to lean wastes in this analysis in order to show their connections, it is not necessarily important to directly trace 
$\mathrm{CO}_{2}$ back to lean wastes in the measurement stage of this method.

\subsection{Conversion Factors}

In this research, greenhouse gas emissions are measured in units of carbon dioxide equivalent $\left(\mathrm{CO}_{2} \mathrm{E}\right)$. Greenhouse gasses are compared in terms of their global warming potential (GWP), or how much heat they are capable of trapping, in relation to other gasses. Carbon dioxide is the reference gas; 1 kilogram of $\mathrm{CO}_{2}$ has a GWP of 1 while, for example, the same amount of $\mathrm{CH}_{4}$ has a GWP of 21 [3]. Source data gathered from the EPA primarily uses carbon equivalent (CE), which is easily converted back to $\mathrm{CO}_{2} \mathrm{E}$ in order to retain consistency with current carbon footprint calculators.

Transportation fuel emissions conversion factors were found at carbonfund.org, part of a list of factors used in the carbon footprint calculator on the same site [23]. These were listed in pounds $\mathrm{CO}_{2}$ per ton-mile, and did not need to be converted.

The Solid Waste Management and Greenhouse Gases report by the EPA provides carbon coefficients of fuels used in heating, transportation, and electricity generation, as well as carbon equivalent footprints of twenty-one common single-material wastes [3]. Using the carbon coefficients of fuels provided in this report, units were converted to better reflect the metrics used in typical companies. For example, in Table 8 emissions from energy usage were converted from kilograms CE per million Btu to pounds $\mathrm{CO}_{2} \mathrm{E}$ per kilowatt-hour. This will allow users to work with familiar units on a scale appropriate to their needs.
This EPA report investigated the amounts of various types of energy used in the production and transportation of each of these wastes, along with non-energy emissions from the process. One material analyzed was aluminum-specifically aluminum cans. Based on the current average of $51 \%$ recycled inputs, 2.24 metric tons of carbon equivalent (MTCE) are produced for every short ton of aluminum cans [3]. A simple conversion can put this in terms of carbon dioxide equivalent. Since $\mathrm{CO}_{2}$ is $12 / 44$ carbon by weight, it can be calculated that every ton of aluminum cans produced has a carbon footprint equal to 8.30 short tons of carbon dioxide equivalent $\left(\mathrm{CO}_{2} \mathrm{E}\right)$.

Also found in this report was data on waste management methods, which was used to account for the effects of recycling, incinerating, or landfilling on the carbon footprint of a lean manufacturing process. The EPA generated a table of relative carbon emissions for various methods of disposal, including recycling, landfilling, and combustion. These emissions were calculated from the moment of disposal, and in some cases account for credits, which measure, for instance, the emissions saved when replacing virgin inputs with recycled material. Because of these credits, the recycling option for most materials is represented by a negative number. It is beyond the scope of this research to account for credits, and therefore the emissions from garbage in this research will reflect a broader view, accounting for the manufacture and disposal of the material, as shown in Tables 9 and $\mathbf{1 0 .}$ The full table of conversion factors appears in Table $\mathbf{1 1}$. Tables A1 and A2 in the appendix display these conversion factors in context of the lean wastes they relate to.

Table 8. Energy emissions conversion factors.

\begin{tabular}{lcccc}
\hline Fuel type & $\mathrm{kg} \mathrm{CE}$ per million Btu & $\mathrm{kg} \mathrm{CO}_{2} \mathrm{E}$ per million Btu & $\mathrm{lb} \mathrm{CO}_{2} \mathrm{E} \mathrm{per} \mathrm{million} \mathrm{Btu}$ & $\mathrm{lb} \mathrm{CO} \mathrm{E} \mathrm{per} \mathrm{kWh}$ \\
\hline Gasoline & 19.15 & 70.93 & 156.36 & 0.53 \\
Diesel & 19.75 & 73.15 & 161.26 & 0.55 \\
National average fuel mix for electricity & 15.83 & 58.63 & 129.26 & 0.44 \\
Natural gas & 14.33 & 53.07 & 117.01 & 0.40 \\
\hline
\end{tabular}

Table 9. Garbage emissions conversion factors.

\begin{tabular}{cccccc}
\hline \multicolumn{2}{c}{ Garbage disposal } & MTCE/ton & \multicolumn{3}{c}{ MTCE/ton, from moment of discard } \\
\hline Material & Type & Manufacture & Recycling & Combustion & Land-filling \\
\hline Aluminum & & 2.24 & -3.70 & 0.02 & 0.01 \\
Steel & & 0.87 & -0.49 & -0.42 & 0.01 \\
Copper & 2.00 & -1.34 & 0.01 & 0.01 \\
& HDPE & 0.49 & -0.38 & 0.25 & 0.01 \\
Plastic & LDPE & 0.62 & -0.46 & 0.25 & 0.01 \\
& PET & 0.57 & -0.42 & 0.30 & 0.01 \\
\hline
\end{tabular}


Table 10. Garbage emissions conversion factors (2).

\begin{tabular}{|c|c|c|c|c|c|}
\hline \multicolumn{3}{|c|}{ MTCE/ton, including manufacture } & \multicolumn{3}{|c|}{ lb. $\mathrm{CO}_{2} \mathrm{E} / \mathrm{lb}$, including manufacture } \\
\hline Recycling & Combustion & Land-filling & Recycling & Combustion & Land-filling \\
\hline-1.46 & 2.26 & 2.25 & -4.91 & 7.59 & 7.56 \\
\hline 0.38 & 0.45 & 0.88 & 1.28 & 1.51 & 2.96 \\
\hline 0.66 & 2.01 & 2.01 & 2.22 & 6.75 & 6.75 \\
\hline 0.11 & 0.74 & 0.50 & 0.37 & 2.49 & 1.68 \\
\hline 0.16 & 0.87 & 0.63 & 0.54 & 2.92 & 2.12 \\
\hline 0.15 & 0.87 & 0.58 & 0.50 & 2.92 & 1.95 \\
\hline
\end{tabular}

Table 11. Green waste conversion factors.

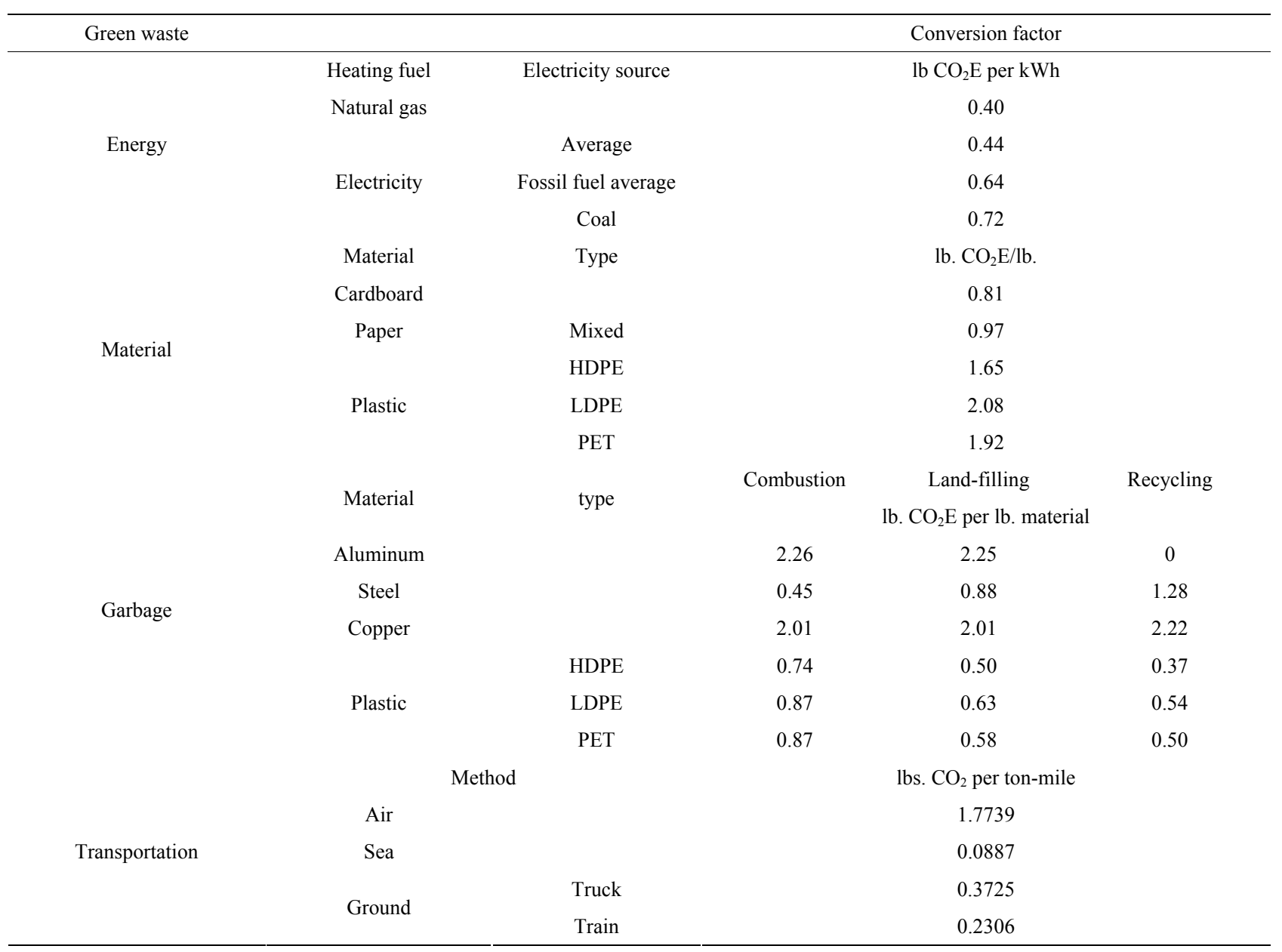

\subsection{Incorporating Green Wastes in Value Stream Mapping}

Already a proven tool for recording material and information flows, as well as timing and inventory data of a process, value stream mapping is a logical way to identify the wastes to be converted into carbon emissions $[3,4]$. To this end, additional data must be selected for inclusion in the current state value stream map.

Possibly the most prevalent green waste is energy, which is used to operate machinery, computers, and to provide heat and light. It is therefore important to incurporate information on the power, time, and energy source of each step in the process. As described in Section 3.1, energy is also related to inventory. Value stream maps already track inventory flow, so by adding details of energy usage to heat, cool, and light the storage space along with the percentage of space the inventory from each value stream activity occupies, a fraction of the energy waste can be appropriated to each batch of inventory.

Materials and garbage are also significant green cate- 
gories, yet are not well represented in standard value stream maps. Weights of raw materials and scrap, or anything that is discarded, should be recorded by material type and method of disposal.

Transportation is generally included on value stream maps as far as final shipping to the customer. It is an important logistical step of the process, and also a source of green waste. In order to simplify measurements, the weight and distance of each shipment, along with the method of shipping, should be noted on the current state value stream map.

\subsection{Summary of Implementation}

The method developed in this research can be implemented into a company's production process in a few low effort steps.

First, a value stream is outlined in the traditional lean fashion, as in Learning to See [13]. During the data collection phase of the current state map, green waste metrics are recorded in addition to the usual data. These metrics are noted below in Table 12. In short, green waste metrics should focus on energy, material, garbage, and transportation for each value stream activity and can be recorded on the VSM. It is important to include the inventory subcategory of energy, which requires data on energy use in the storage area, as well as the percentage of that area used by the inventory from each activity.

Once the data is obtained, green metrics are plugged into the conversion table and combined with the conversion factors to translate the various metrics into their $\mathrm{CO}_{2} \mathrm{E}$ equivalents. This will provide a carbon footprint for the company, and allow them to see the relative effects of various wastes. Such comparisons will be helpful in determining which reductions will have the most impact on emissions.

At this point the lean waste reduction process continues as usual. A future state map is outlined, following the lean principles of creating flow and establishing pull [7, 13]. The future state is implemented, and thus becomes the new current state. After a time - a matter of weeks or months to establish the new state-a new current state value stream map is created in order to record the new data. New current state data is converted to $\mathrm{CO}_{2} \mathrm{E}$ and then compared to the original current state in order to track the green effects of lean improvements.

Table 12. Addition data for value stream.

\begin{tabular}{cccc}
\hline Green waste & Unit of measure & \multicolumn{2}{c}{ Required info } \\
\hline Energy & $\mathrm{kWh}$ & Source & Storage energy, \% \\
Material & lbs. & Type & \\
Garbage & lbs. & Type & Disposal \\
Transportation & tons & Miles & Mode of transport \\
\hline
\end{tabular}

\section{Case Study}

In order to illustrate the method proposed in this paper, a case study was performed using an example value stream found in Learning to See [13]. The current state value stream map, is based on a fictional company manufacturing stamped-steel steering brackets for cars. This example is of a standard value stream map and therefore does not include green metrics. This case study uses data from the VSM, additional information found in Learning to See, and some assumed values in order to demonstrate the proposed method. In practice all of this information will be collected together in a walk through of the value stream, but using an existing VSM also highlights the data missing from the standard tool that is needed to make green calculations. This example will evaluate each value stream activity for green wastes and record the relevant data to be converted to $\mathrm{CO}_{2} \mathrm{E}$ emissions.

The receiving portion of the VSM shows $500 \mathrm{ft}$ coils of steel arriving by truck every Tuesday and Thursday. Those coils are stored for five days before moving to Stamping. From this information it is evident that there is both transportation and energy waste (by way of inventtory) in this step. If each coil weights one ton and is shipped 30 miles by truck, using the conversion factor from Table 11 it is calculated that this accounts for 11.18 lbs. of $\mathrm{CO}_{2}$ twice a week. The weight and distance data is recorded on the VSM and then entered on a spreadsheet, such as the one in the appendix, to simplify calculations.

Inventory data for this step must also be recorded. Suppose lighting and heating the storage area requires 10 $\mathrm{kW}$ of electricity and the coils occupy $40 \%$ of the storage area for five days. With a conversion factor of $0.44 \mathrm{lbs}$. $\mathrm{CO}_{2} \mathrm{E}$ per $\mathrm{kWh}$, storing these coils accounts for $140.80 \mathrm{lb}$ $\mathrm{CO}_{2} \mathrm{E}$ over five days. Inventory is calculated in a similar manner throughout the remaining value stream activities.

Stamping includes two shifts, or sixteen hours, of machine use. If the stamping machine uses $11 \mathrm{~kW}$ of electricity, its $\mathrm{CO}_{2} \mathrm{E}$ emissions can be easily calculated with the use of conversion factors. This value stream activity also produces garbage - scraps of steel that are collected and sent to be recycled. Assuming $75 \mathrm{lbs}$. of steel each day and given recycling accounts for $1.28 \mathrm{lbs}$. $\mathrm{CO}_{2} \mathrm{E}$ per lb. steel, that is $96 \mathrm{lb} . \mathrm{CO}_{2}$.

This value stream map shows that finished products are shipped daily, at a total of 18,400 pieces each month, in trays of 20 (a total of 920 trays). In order to calculate the carbon footprint for this step we must know the shipping method, weight and distance of the shipment, none of which is included in this map. Assuming that 30 trays totaling 0.5 tons are shipped by truck 100 miles each day, we can calculate using the conversion factor (see Table 11) that $18.625 \mathrm{lbs}$. of $\mathrm{CO}_{2}$ are emitted by this process each day. 
Overall, this case study shows an example of a standard value stream map not providing all of the necessary data to calculate emissions, although it does show the capability to do so. By including the additional data identified, value stream mapping is a valuable tool in quantifying carbon footprints.

\section{Conclusions}

This paper demonstrates how the carbon footprint of a manufacturing process can be measured by viewing green wastes as an outcome of lean waste and including additional data in the traditional value stream mapping process. The unit conversions provided allow companies to utilize information directly from their value stream map. Focusing on emissions in terms of lean waste and utilizing existing tools such as value stream maps with only slight modifications allows for results with little additional effort on the part of these companies. By comparing current states over time, companies can see the amount of carbon emissions that have been saved.

Given the impending legislation on emissions regulation, as well as growing consumer demand for green products, it is more important than ever for companies to reduce their environmental impact. A step has been made toward carbon measurement using lean waste principles. Lean manufacturing technology can serve as a mechanism to make companies compliant with impending legislation.

The initial efforts in quantifying the carbon footprint of lean wastes have been outlined in this paper, yet there is still much work that can be done to advance the technique. Conversion factors must be validated to ensure accuracy. More options for materials, including hazardous wastes, should be added, and further organizing these metrics into an integrated calculator tool will greatly help companies in accessing the information. Additionally, the value stream mapping procedure of green waste identification must be standardized. At present this technique is intended for comparing green waste before and after initiating lean changes, and is not meant to fully address potential government regulations. With further study this first step in quantifying green waste from lean categories will prove a significant advance in terms of both lean and green manufacturing.

\section{REFERENCES}

[1] K. Sheppard, "Everything You Always Wanted to Know about the Waxman-Markey Energy/climate Bill-In Bullet Points," Grist Magazine, Inc., 2009. http://www.grist.org/article/2009-06-03-waxman-markeybill-breakdown

[2] B. Wills, "Green Intentions: Creating a Green Value Stream to Compete and Win," CRC, Boca Raton, 2009.
[3] US Environmental Protection Agency, "The Lean and Environment Toolkit," 2006.

[4] US Environmental Protection Agency, "The Lean and Energy Toolkit," 2007.

[5] IPCC, "Organization," Intergovernmental Panel on Climate Change, 2011.

[6] S. Solomon, D. Qin, M. Manning, Z. Chen, M. Marquis, K. B. Averyt, M. Tignor and H. L. Miller, "Contribution of Working Group I to the Fourth Assessment Report of the Intergovernmental Panel on Climate Change," Cambridge UP, Cambridge, 2007.

[7] Lean Enterprise Institute, "What Is Lean-Principles," Lean Enterprise Institute, Inc., 2009.

http://www.lean.org/WhatsLean/Principles.cfm

[8] US Environmental Protection Agency, "Lean and the Environment," US Environmental Protection Agency, 2011.

[9] C. Reed and US Environmental Protection Agency, "Industry Week: Using Lean Activities to Target Environmental Concerns," 2010.

[10] J. P. Womack, D. T. Jones and D. Roos, "The Machine That Changed the World: Based on the Massachusetts Institute of Technology 5-Million Dollar 5-Year Study on the Future of the Automobile," Rawson Associates, New York, 1990.

[11] J. P. Womack and D. T. Jones, "Lean Thinking: Banish Waste and Create Wealth in Your Corporation," Simon \& Schuster, New York, 1996.

[12] M. Franchetti, "Lean and Green," Industrial Engineer, 2009, pp. 24-29.

[13] M. Rother and J. Shook, "Learning to See: Value Stream Mapping to Create Value and Eliminate Muda," Learning Enterprise Institute, Brookline, 1999.

[14] J. Kluger, "The 50 Best Inventions of 2009," Time Inc., 2009.

[15] Global Footprint Network, "Personal Footprint," Global Footprint Network, 2009.

http://www.footprintnetwork.org/en/index.php/GFN/page/ personal_footprint/

[16] The Nature Conservancy, "Carbon Footprint Calculator," The Nature Conservancy, 2010. http://www.nature.org/greenliving/carboncalculator/

[17] “Carbon Dioxide Emissions Calculator,” 2010. http://www.carbonify.com/carbon-calculator.htm

[18] Carbon Footprint, "Carbon Footprint Calculator," Carbon Footprint Ltd., 2010.

http://www.carbonfootprint.com/calculator.aspx

[19] "CarbonMe Business Calculator," 2007. http://www.carbonme.org/carbonmebus_calculator.php

[20] The Climate Trust, "Business and Organization Carbon Calculator," The Climate Trust, 2010. http://www.climatetrust.org/

[21] Seattle Climate Partnership, "Tool for Assessing Your Business's Carbon Footprint," 2010. http://www.seattleclimatepartnership.org/resources/index. html

[22] T. Epply and J. Nagengast, "The Lean Manufacturing 
Handbook," 2010.

http://continental-design.com/lean-manufacturing/handbo ok-1.html
[23] "How We Calculate Your Carbon Footprint," 2010. http://www.carbonfund.org/site/pages/carbon_calculators/ category/Assumptions

\section{Appendix}

Table A1. Conversion factors for lean wastes (other than specific storage wastes).

\begin{tabular}{|c|c|c|c|c|c|c|}
\hline \multirow{11}{*}{ Transport } & \multirow{5}{*}{ Transportation } & \multicolumn{2}{|r|}{ Method } & \multicolumn{3}{|c|}{ lbs. $\mathrm{CO}_{2}$ per ton-mile } \\
\hline & & Air & & & 1.7739 & \\
\hline & & Sea & & \multicolumn{3}{|c|}{0.0887} \\
\hline & & \multirow{2}{*}{ Ground } & Truck & \multicolumn{3}{|c|}{0.3725} \\
\hline & & & Train & \multicolumn{3}{|c|}{0.2306} \\
\hline & \multirow{6}{*}{ Material } & \multirow{4}{*}{$\begin{array}{c}\text { Material } \\
\text { Cardboard } \\
\text { Paper }\end{array}$} & \multirow[t]{2}{*}{ Type } & \multicolumn{3}{|c|}{ lb. $\mathrm{CO}_{2} \mathrm{E} / \mathrm{lb}$} \\
\hline & & & & \multicolumn{3}{|c|}{0.81} \\
\hline & & & Mixed & \multicolumn{3}{|c|}{0.97} \\
\hline & & & HDPE & \multicolumn{3}{|c|}{1.65} \\
\hline & & \multirow[t]{2}{*}{ Plastic } & LDPE & \multicolumn{3}{|c|}{2.08} \\
\hline & & & PET & \multicolumn{3}{|c|}{1.92} \\
\hline \multirow{12}{*}{ Defects } & \multirow{7}{*}{ Garbage } & Material & type & Recycling & $\begin{array}{c}\text { Combustion } \\
\text { lb. } \mathrm{CO}_{2} \mathrm{E} \text { per lb. material }\end{array}$ & Land-filling \\
\hline & & Aluminum & & 0 & 7.59 & 7.56 \\
\hline & & Steel & & 1.28 & 1.51 & 2.96 \\
\hline & & Copper & & 2.22 & 6.75 & 6.75 \\
\hline & & & HDPE & 0.37 & 2.49 & 1.68 \\
\hline & & Plastic & LDPE & 0.54 & 2.92 & 2.12 \\
\hline & & & PET & 0.50 & 2.92 & 1.95 \\
\hline & & Heating fuel & Electricity source & & lb $\mathrm{CO}_{2} \mathrm{E}$ per kWh & \\
\hline & & Natural gas & & & 0.40 & \\
\hline & Energy & & Average & & 0.44 & \\
\hline & & Electricity & Fossil fuel average & & 0.64 & \\
\hline & & & Coal & & 0.72 & \\
\hline & & Heating fuel & Electricity source & & lb $\mathrm{CO}_{2} \mathrm{E}$ per $\mathrm{kWh}$ & \\
\hline & & Natural gas & & & 0.40 & \\
\hline Over Production & Energy & & Average & & 0.44 & \\
\hline & & Electricity & Fossil fuel average & & 0.64 & \\
\hline & & & Coal & & 0.72 & \\
\hline & & Heating fuel & Electricity source & & lb $\mathrm{CO}_{2} \mathrm{E}$ per kWh & \\
\hline & & Natural gas & & & 0.40 & \\
\hline Inventory & Energy & & Average & & 0.44 & \\
\hline & & Electricity & Fossil fuel average & & 0.64 & \\
\hline & & & Coal & & 0.72 & \\
\hline & & Type & Disposal & Recycling & $\begin{array}{c}\text { Combustion } \\
\text { lb. } \mathrm{CO}_{2} \mathrm{E} \text { per lb. material }\end{array}$ & Land-filling \\
\hline & & Aluminum & & 0 & 7.59 & 7.56 \\
\hline & & Steel & & 1.28 & 1.51 & 2.96 \\
\hline Miotion & Garbage & Copper & & 2.22 & 6.75 & 6.75 \\
\hline & & & HDPE & 0.37 & 2.49 & 1.68 \\
\hline & & Plastic & LDPE & 0.54 & 2.92 & 2.12 \\
\hline & & & PET & 0.50 & 2.92 & 1.95 \\
\hline & & $\begin{array}{l}\text { Heating fuel } \\
\text { Natural gas }\end{array}$ & Electricity source & & $\begin{array}{c}\text { lb CO } \mathbf{C O}_{2} \mathbf{E} \text { per } \mathbf{k W h} \\
0.40\end{array}$ & \\
\hline Over Processing & Energy & & Average & & 0.44 & \\
\hline & & Electricity & Fossil fuel average & & 0.64 & \\
\hline & & & Coal & & 0.72 & \\
\hline & & Heating fuel & Electricity source & & lb $\mathrm{CO}_{2} \mathrm{E}$ per $\mathrm{kWh}$ & \\
\hline & & Natural gas & & & 0.40 & \\
\hline Waiting & Energy & & Average & & 0.44 & \\
\hline & & Electricity & Fossil fuel average & & 0.64 & \\
\hline & & & Coal & & 0.72 & \\
\hline
\end{tabular}


Table A2. Conversion factors for specific storage wastes.

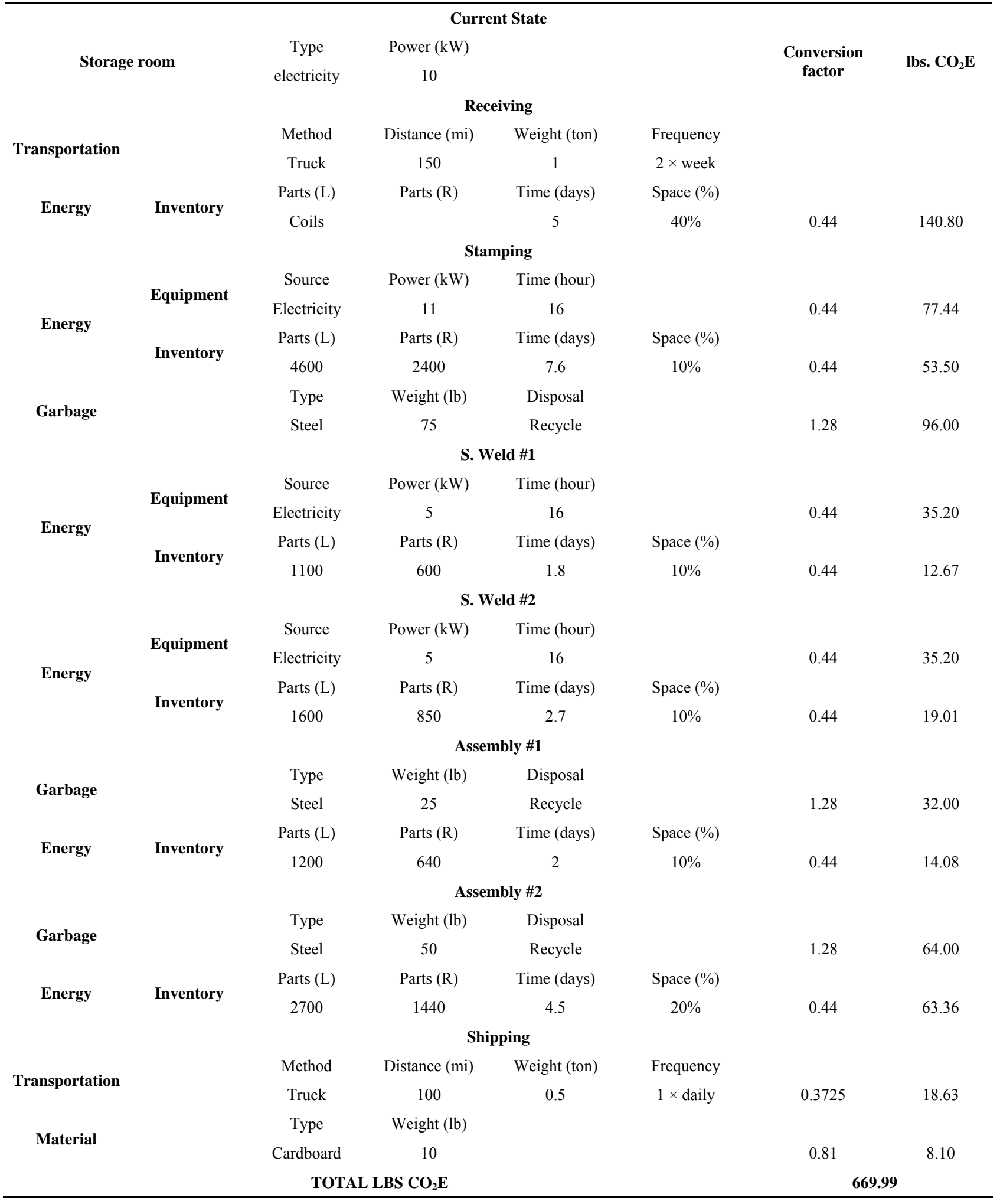

